We read the water meters about once a week. Emitter flow and uniformity were measured on March 21, June 21, and August 7. Yield data were taken for each plot from March through May. Weekly and monthly reference evapotranspiration (ETo) data were obtained from the CIMIS weather stations in Santa Maria.

\section{Results}

The applied water data (ETaw, table 1) showed a trend of lower flow rates in the untreated plots. Figure 1 shows the flow rates of polymer-treated and untreated waters on March 1, March 21, June 21, and August 7. Emission evaluations of polymertreated water show only slight decreases over the 6-month growing period, but untreated well waters show a decrease of nearly $50 \%$ by August. A linear regression of flow rate versus time was fitted for both treated and untreated plots. The test for equality of slopes demonstrated that the decrease in flow rate over time for untreated water was significantly greater than for treated water at the $1 \%$ level.

\section{Conclusions}

The results (table 1, fig. 1) indicate that the system injected with $2 \mathrm{mg} / \mathrm{L}$ maleic anhydride polymer supplied the actual amount of water required for plant needs, while the untreated tubing's output decreased as the season progressed. The crop water requirement (ETc) for strawberries and the flow rate differences are shown as hours of irrigation in table 2. The hours of irrigation needed to apply a given amount of seasonal water are much greater for the untreated than the treated system.

The yield from each individual plot was obtained for the period from March 1989 to May 19, 1989, and the yields from the aggregated plots (10 acres), from May 20 to August 20, 1989 (table 3). A yield increase of about 300 12-pound trays per 2.5 acre plot was obtained in the early season. Assuming this trend continued, an overall yield increase of about 600 trays would result where the aggregated yield was assigned to each 2.5 acre plot and added to the early season results. This suggests that the plots treated with $2 \mathrm{mg} / \mathrm{L}$ maleic anhydride polymer received the appropriateamount of irrigation water. Yields were increased and drip efficiency improved where we injected the polymer into drip irrigation lines.

J. L. Meyer is Irrigation and Soils Specialist and R. A. Strohman is Staff Research Associate, UC Riverside; M. J. Snyder is Farm Advisor, Santa Barbara County;L.H. Valenzuela is Farm Advisor, Santa Barbara County; and A. Harris is with Ciba-Geigy, Manchester, United Kingdom.

Theauthorswish toacknowledge the valuable assistance provided by growers Ronald Burkand Robert Espiñola of Gold Coast Farms, and by Olocco Ag Services, Santa Maria, California.

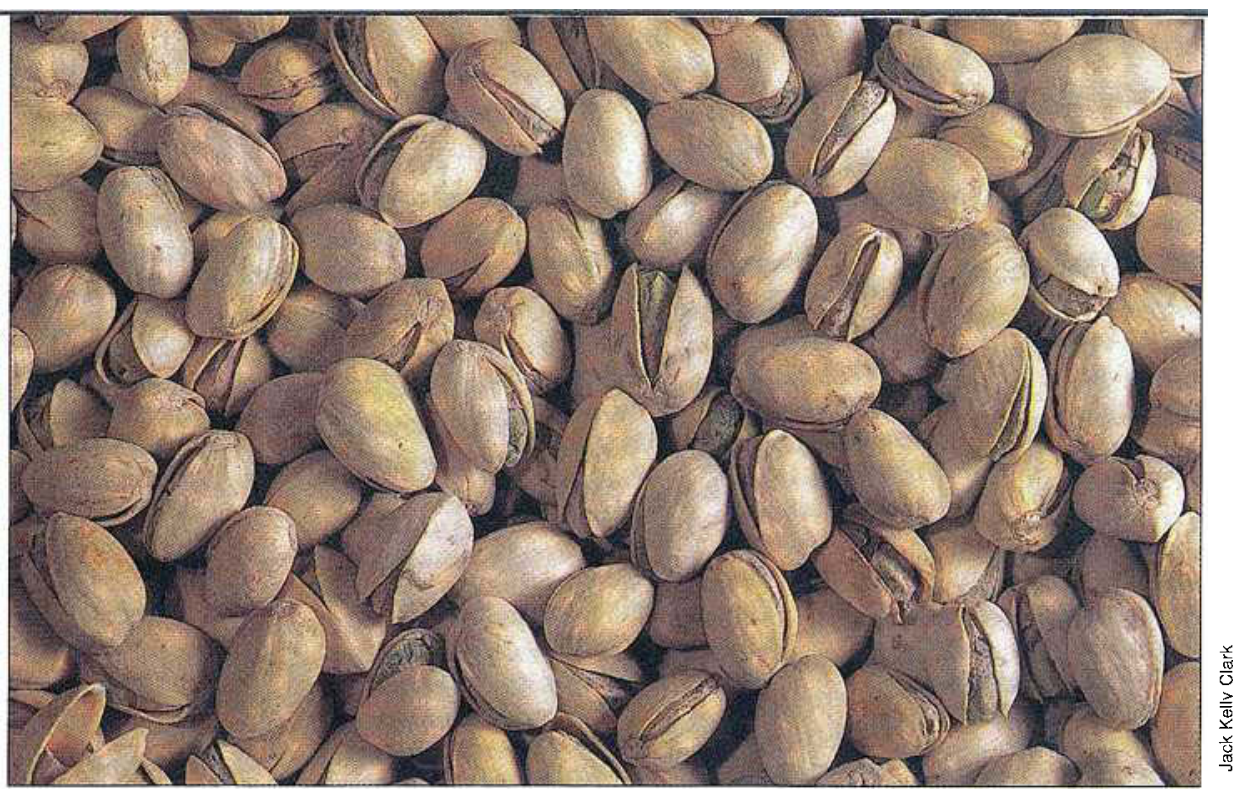

\title{
A shoppers' survey: California nuts and produce, food quality, and food safety
}

\author{
Marciel A. Pastore $\square \quad$ Christine M. Bruhn
}

795 consumers interviewed at 53

California markets gave a variety of reasons for buying the way they do. Many had their own ideas about what indicates good quality in produce, but had trouble putting those ideas into words. Consumer ideas about food safety were easier to articulate.

Consumer interest in fresh produce is high. Researchers report that people are changing their eating habits to increase their intake of produce, and this attitude is reflected in different purchasing patterns.

The guiding factors in food choice are quality, nutritive value, and safety. Consumer concerns about produce safety primarily with respect to pesticide and chemical residues - have been the focuses of recent research. When specifically asked, about $80 \%$ of consumers in a nationwide survey considered residues to constitute a serious hazard. In the past two years, almost $20 \%$ of consumers have transformed their concern into action, and have altered their purchasing patterns to include the purchase of organicorcertified "residue-free" produce.

Little research focusing on consumers' perception of quality has been completed. Consumers have identified products that are "inconsistent" in quality, but their criteria for quality have not been identified. Although brand-name produce has been available for some time, consumers do not place a lot of emphasis on brands when it comes to purchasing. Fewer than half of consumers consider a brand-name item to be superior in quality to those without brands. Other researchers havenotmeasured the influences of consumer identification and use of other indicators of producequality, such as color, texture, and stage of maturity.

We undertook this study to determine the selection criteria of California consumers and their attitudes toward specific California specialty crops.

\section{Method}

The first author personally interviewed 795 consumers in an open-ended questionnaire at 53 sites throughout California. Cities were selected at random within population parameters. Six stores were selected as interview sites in each of five cities with populations over 50,000 (Citrus Heights, Fremont, Los Angeles, Ontario, and San Bernardino). We selected three stores from each of five cities, unincorporated areas, or polling districts with populations between 500 and 50,000 (Carmichael, Santa Cruz, San Gabriel, Citrus Heights, and Cardiff by the Sea). We also selected one store in each of eight cities or unincorporated areas with populations under 500 . Stores were randomly selected from the telephonedirectory. Weconducted interviews in the produce department of each store between February and July 1987. Fifteen consumers were randomly selected for interview at each survey site.

Consumers wereasked to recall thenumber of times they had purchased selected 
crops within the preceding six months, how they used the commodity, and how they determined itsquality. In addition, weasked them whether they had any concerns about the safety of the foods they purchased. The surveyed crops were almonds, walnuts, pistachios, beets, broccoli, Brussels sprouts, cabbage, cauliflower, canned and fresh peaches, and canned tomato products. Interview data were analyzed using Dbase III+ software.

\section{The sample}

Three-fourths of the people we interviewed were female. Age distribution for the sample was comparable to that of the general population, although younger persons were underrepresented and persons over 60 years old wereoverrepresented (table 1). Although more respondents were from southern than from northern California, southern California consumers were underrepresented relative to the general population. Ninetyfive percent of those sampled either shared food shopping responsibilities or were the principle food shopper in their family unit. Sampled shoppers were primarily Caucasian, although other ethnic groups were included. We did not determine income information in our interviews.

\section{California nut purchases}

Walnuts, almonds, and pistachios are purchased by 36,36 , and $28 \%$ of consumers, respectively. Althoughalmond commercials urge consumers to buy "a can a week," only $7 \%$ of almond buyers report buying the nuts two or more times a month.

TABLE 1. Demographic information (total sample: $n=795$ )

\begin{tabular}{lcc}
\hline \hline Classification & $\begin{array}{c}\text { Proportion } \\
\text { of our } \\
\text { sample }\end{array}$ & $\begin{array}{c}\text { Proportion } \\
\text { of state } \\
\text { population }\end{array}$ \\
\hline Location & & $\%$ \\
N. California & & \\
$\quad$ ( $=375)$ & 47.0 & 41.0 \\
S. California & & \\
$\quad$ ( $n=420)$ & 53.0 & 59.0 \\
Age & & \\
<30 years & 14.6 & 29.3 \\
30-59 years & 47.7 & 49.8 \\
$\geq 60$ years & 37.7 & 20.9 \\
Ethnicity & & \\
Caucasian & 84.6 & 57.0 \\
Hispanic & 6.8 & 19.2 \\
Black & 4.2 & 7.7 \\
Asian & 3.6 & 5.0 \\
Other & 0.8 & 11.1 \\
Sex & & \\
Female & 76.2 & NA \\
Male & 23.8 & NA \\
Main shopper in family? & & \\
Yes & 89.0 & \\
No & 4.8 & \\
Shared shopping & 6.2 & \\
\hline
\end{tabular}

Most of the nut buyers we interviewed purchase these three nuts only once or twice a year. The walnut is the most frequently purchased, and shoppers store them for use throughout the year. Eighty percent of the interviewed almond buyers buy only shelled almonds. They mainly use almonds for snacking; consumers rely on a brand name for quality. Walnut buyers use walnuts for baking and for snacking.

Significantly more southern Californians than northern Californians buy walnuts. Among those whodo not buy walnuts, more northern Californians grow their own walnuts or are given walnuts by friends who grow their own.

Most interviewed consumers who buy nuts in the shell indicated that they have no idea how to judge nut quality, and just buy whatever is available. This is true for all three kinds of nut. When asked to describe quality criteria for shelled nuts, consumers indicated that they look at the condition of the nut meat, avoiding shriveled nuts or, as they described it, "chipped nuts and little broken pieces"; others bought whatever was available.

Consumers said they got addicted to pistachios. Ninety-five percent of the interviewed shoppers who buy pistachios eat them as snacks. Many eat all their pistachios in one sitting. Some adults hide them from their children because they feel pistachios are too expensive a snack; they choose to keep the nuts to themselves. One respondent claimed to hide in the closet and eat them so the family wouldn't know there were pistachios in the house.

Shoppers whodidn'tbuy any of the three nuts gave various reasons why. Some cited preference for other nuts (mainly peanuts or cashews), others the belief that nuts are too fattening, and still others cited health factors (e.g., dentures) that prevented their eating nuts. Some indicated that, because they no longer bake, they do not need to buy nuts.

\section{Produce}

The sampled shoppers are very fond of vegetables. Broccoli is purchased by more consumers $(92 \%)$ than any other vegetable included in the survey. Forty-seven percent of those interviewed buy broccoli at least once a week. Cabbage and cauliflower are purchased by 81 and $79 \%$ of the shoppers, respectively. Over half of those who buy broccoli, cauliflower, and cabbage enjoy eating them both raw and cooked. Brussels sprouts, purchased by $47 \%$ of consumers, rank least favorite among the vegetables surveyed. In our sample, a higher proportion of males than females like Brussels sprouts.

In general, a shopper who dislikes a particular vegetable will not buy it, even though another adult in the household likes it. Brussels sprouts is the exception. Some consum- ers who dislike Brussels sprouts still serve them at Thanksgiving dinner, out of tradition.

Interviewed shoppers had difficulty describing the characteristics they look for in raw vegetables. Many would say "fresh you know, fresh," and others seemed to know exactly what they were looking for, even if they couldn't put it into words.

Broccoli buyers most often look for color. Preferred colors range from dark green to blue-green. Other shoppers look at the condition of the broccoli head. They do not want florets that are crushed, dried out, or going to seed. Still others look for broccoli stalks that are short or thin.

There was some confusion about the appropriate color for broccoli florets and whether they should be opened or closed. Some consumers indicated a preference for purple heads, whereas others never buy broccoli with purpleheads. One interviewed shopper prefers yellow florets.

Shoppers also use color as an indicator of quality for cauliflower. They insist on a white to cream-colored head with no black or brown spots, which they usually referred to as "mold."

Cabbage buyers in our sample seem to feel that cabbage is cabbage, and that there is no real difference among heads. They either buy whatever is available or they look for a head of a particular size. Most interviewed shoppers prefer small to medium-sized heads. Some generally prefer a firm head of cabbage unless they are making stuffed cabbage rolls, in which case they prefer a looser head.

Only $37 \%$ of beet buyers purchase fresh beets. Most said they eat the tops as well as the root. They prefer small to medium-sized beets with tender tops, and they choose plants that have no bug holes, either in the tops or in the root. Those who do not buy fresh beets either said that they don't know how to prepare beets or that beets are too messy to prepare.

Brussels sprouts buyers prefer small to medium-sized sprouts, and look for freshness and tight, firm leaves.

Three out of four people interviewed purchase fresh peaches. Significantly more northern Californians than southern Californians buy fresh peaches - $80 \%$ compared to $69 \%$. Consumers had difficulty describing their criteria for assessing peach quality. When we asked whether they prefer their peaches firm or ripe, $60 \%$ of the sample preferred ripe peaches, $34 \%$ preferred firm peaches. The remaining shoppers indicated that they judge peaches based on varietal or color indicators. Significantly more southern Californians than northern Californians prefer to purchase firm peaches $-41 \%$ compared to $23 \%(\mathrm{P}<0.001)$. Correspondingly, more northern Californians prefer ripe peaches $-66 \%$ compared to $55 \%(\mathrm{P}<0.01)$. 
Canned peaches are purchased by $56 \%$ of the sample, and we found no significant difference between the buying patterns of northern and southern Californians. Half of the consumers surveyed purchase canned peaches by brand; one-quarter of them choose according to price. The other onequarter of consumers showed no clear pattern to their purchases of canned peaches.

The shoppers who buy frozen vegetables said they rely on a brand name for product quality. Many buy frozen vegetables in quantity when prices are reduced.

Almost everyone surveyed - 96\% buys one or more canned tomato products. Many of the shoppers buy tomato products in quantity when prices are reduced. Catsup ranks at the top of the list of frequently purchased tomato products; almost $90 \%$ of consumers buy this item (table 2). Catsup is the one product for which respondents said they can really taste a difference among different brands. These consumers rely on a brand name for quality. Tomato sauce and whole, sliced, or stewed tomatoes are purchased by almost three-quarters of the shoppers interviewed.

Over half $(57 \%)$ of our respondents who buy canned tomato products rely on a brand name for quality. Thirty-five percent feel that most canned tomato products are the same, and choose according to price; the remainder purchase whatever is available. Significantly more female shoppers over age 30 rely on brand names for quality in tomato products.

Although the shoppers we interviewed said they rely on a brand name for quality in canned and frozen vegetables, most could not recall the brand name they prefer. Rather than the name, they recognized the label on the shelf.

\section{Safety}

The last question we asked was: "Do you have any concerns about the safety of the food you buy in California, including canned goods, baked goods, dairy foods, frozen foods, meat, fish, poultry, or produce?"

Half of the surveyed consumers indicated concern about food safety. Those who did not either said that they trust the government to maintain food safety or that they feel there is nothing they can do about food

\begin{tabular}{|c|c|}
\hline Product & $\begin{array}{l}\text { Proportion } \\
\text { of sample }\end{array}$ \\
\hline & $\%$ \\
\hline Catsup & 89 \\
\hline Sauce & 84 \\
\hline Whole, sliced, stewed & 73 \\
\hline Juice, including V-8 & 49 \\
\hline Paste & 45 \\
\hline
\end{tabular}

safety. Age was theonly demographic factor with which the level of concern varied. Significantly fewer shoppers (38\%) age 60 and over had food safety concerns compared to those 29 and younger (59\%) and those between 30 and 59 (56\%). Fewer Asian respondents expressed concern about foodsafety than did members of other ethnic groups; however, our small sample sizes for these groups preclude any statistical significance.

Almost half $(46 \%)$ of the interviewed shoppers who indicated concern about the safety of the food they buy voiced specific concerns. More were concerned about the safety of produce than that of any other food group.Sixty-four percent of the respondents' safety concerns related to the field application of chemicals such as pesticides and herbicides. Althoughourinterviews predate the Alar controversy, apples were most often mentioned as objects of this kind of concern. Respondents' concerns focused on the use of waxes and sprays.

Meat products ranked second in number of specific safety concerns. The main concern involves the chemicals added to animal feeds or administered directly to the animals: hormones, steroids, and antibiotics.

Consumers commented on the quality and freshness of meat. Many feel that quality is poor and that meat is kept in the case too long. They also expressed concern about colorings and preservatives they believe are added to meats. Some consumers said they often feel that meat (particularly ground beef) is old, citing its brown color. Others said that ground beef is too red, and that they believe butchers add something to the meat to make it red.

Those who buy fish mentioned their concerns about toxins that get into fish from polluted streams, rivers, lakes, and oceans. These consumers did not know how to tell whether their fish come from polluted waters. Others are concerned about the overall quality and freshness of fish.

Many consumers are concerned about the safety of poultry products. Contamination with Salmonella bacteria during processing was mentioned most frequently. Of those expressing concerns about the safety of poultry, almost half had watched the 60 Minutes television expose on the poultryprocessing industry. They said this program brought the potential hazards to their attention.

Concerns voiced about canned foods include worries about dented cans and about the safety of canned foods in general:bacterial contamination, bulging cans, and the danger of botulism. Even those who expressed no concerns indicated they never buy dented cans.

Few consumers mentioned concerns about the safety of frozen foods. However, they did complain about poor quality, most often mentioning freezer burn.

No one indicated concerns about the safety of baked goods. The shoppers' only concerns about the safety of dairy foods was limited to problems of tampering. Most foodtampering concerns were expressed by southern California consumers.

\section{Conclusions}

Among the vegetables covered in our survey, broccoli, cabbage, cauliflower, and canned tomato products are the most frequently purchased. The market for nuts has room for expansion. As people doless and less baking at home, promotional activities should focus on the use of nuts in other types of dishes and as snacks, as well as their health attributes.

Although consumers have indicated the importance of quality in product selection, their knowledge of reliable indicators of quality is limited. Consumers recognizesigns of wilting in vegetables or shriveling in nuts, but they exhibit a variety of preferences as to size and color. Of particular concern is the relatively low frequency of purchase of fresh peaches and some consumers' preference for firm peaches. This pattern is particularly strong in southern California. Although consumers may prefer toripen fruits at home, a few noted their preference for hard, crunchy peaches; still others complained that the peaches develop little flavor and rot before they ripen.

All in all, ourstudy reveals that consumer concerns about food safety are not simply the result of the Alar controversy. Rather, long-standing unexpressed concerns appear to have been brought to the surface by recent coverage in the mass media. Food safety concerns are greatest for produce, followed by meat, fish, and poultry. Frozen foods, baked goods, and dairy products elicit the least safety concern.

Consumers could benefit from programs that tell how to judgefood quality and safety. Consumer confidence in the safety of the food supply would probably improve if consumers learned more about the regulations and mandated practices that reduce health hazards. These subjects have traditionally been the purview of the home economist and dietician. California agriculture can benefit from a strong program that provides food-quality and safety information to consumers.

Marciel A. Pastore is a Home Economist and Youth Development Advisor, Napa County; and Christine M. Bruhn is a Consumer Food Marketing Specialist, Cooperative Extension, University of California, Davis. The authors gratefully acknowledge statistical assistance provided by Carol Adams. Encouragement from Dean Donaldson was also appreciated. 